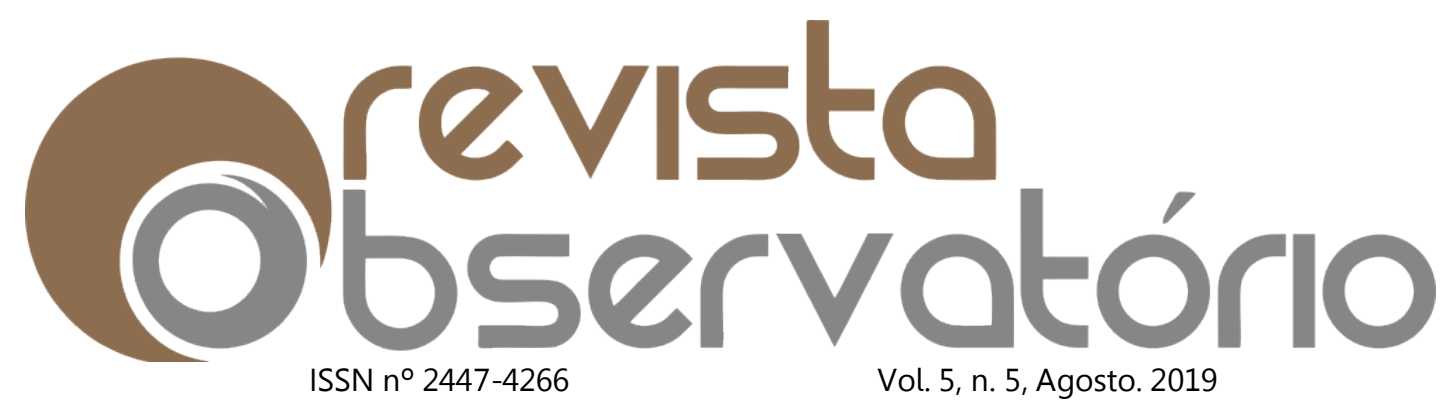

DOI: http://dx.doi.org/10.20873/uft.2447-4266.2019v5n5p454

\section{AJUDE-ME POR FAVOR! \\ O efeito da cocriação na \\ persuasão de \\ consumidores}

HELP ME PLEASE! The effect of cocreation on consumer persuasion

¡AYUDAME POR FAVOR! El efecto de la co-creación em la persuasión de consumidores

\author{
Warton da Silva Souza ${ }^{1}$ \\ Melby Karina Zuniga Huertas ${ }^{2}$ \\ Fábio Rogério de Morais ${ }^{3}$ \\ Juliana Moreira Batista ${ }^{4}$
}

\title{
RESUMO
}

$\mathrm{Na}$ revisão da literatura sobre cocriação detectou-se lacunas teóricas relacionadas à resposta do consumidor observador (que não participou do processo de cocriação) aos resultados da cocriação. O objetivo desta pesquisa é estudar o efeito de se informar a cocriação (empresa/consumidor e empresa/especialista) do produto, na persuasão do consumidor observador, considerando-se diferentes apelos de propaganda. Em 2 experimentos foram manipuladas as variáveis "tipo de parceiro de cocriação" (consumidores/ especialistas) e "tipo de apelos da mensagem" (racionais/emocionais). Os

\footnotetext{
${ }^{1}$ Doutor, Mestre e Graduado em Administração. Professor/Pesquisador da Universidade Federal do Tocantins. E-mail: wartonsilva@uft.edu.br.

2 Doutora e Mestra em Administração, Graduação em Ciências Administrativas. Professora/Pesquisador do Programa de Mestrado e Doutorado em Administração do Centro Universitário da FEl. E-mail: mhuertas@fei.edu.br.

${ }^{3}$ Doutor, Mestre e Graduado em Administração. Professor/Pesquisador da Universidade Federal de Rondônia. E-mail: moraisfabiobh@gmail.com.

4 Doutoranda e Mestra em Administração, Graduada em Marketing. Discente no Programa de Doutorado em Administração da EAESP-FGV. E-mail: juliana.batista@fgv.edu.br.
} 


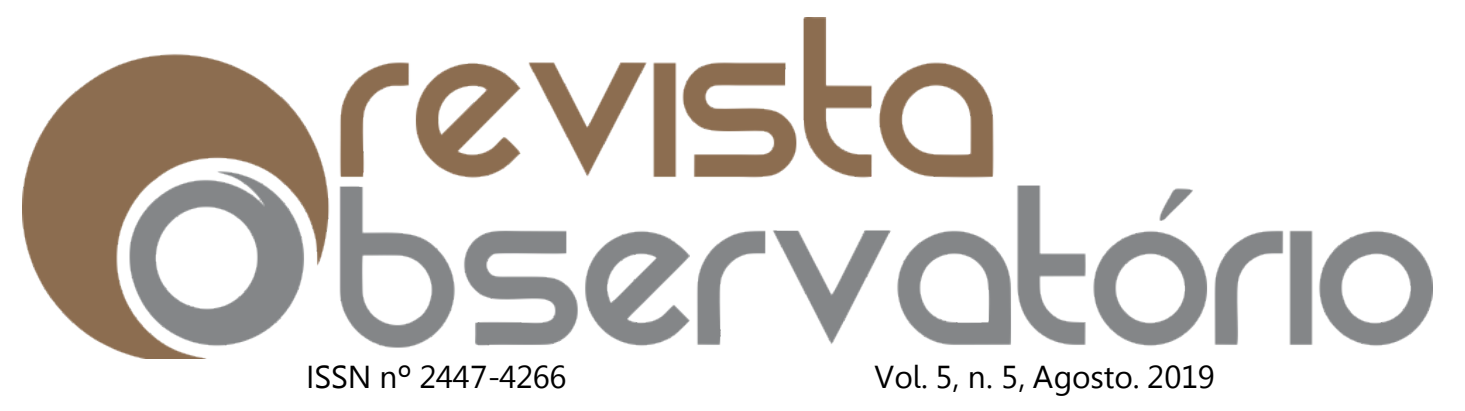

DOI: http://dx.doi.org/10.20873/uft.2447-4266.2019v5n5p454

resultados não comprovaram os efeitos esperados. No entanto, as médias das medidas de persuasão apontam que as hipóteses formuladas podem ser confirmadas em estudos posteriores.

PALAVRAS-CHAVE: Cocriação; Persuasão; Consumidor Observador.

\begin{abstract}
In reviewing the literature on co-creation was detected theoretical gaps related to the observer consumer response (which did not participate in the co-creation process) to co-creation results. The objective of this research is to study the effect of informing the co-creation (company / consumer and company / expert) of the product as an observer consumer persuasion, considering different advertising appeals. In two experiments were manipulated variables "type of co-creation partner" (consumers / experts) and "type of message appeals" (rational / emotional). The results did not confirm the expected effects. However, the means of persuasion measures show that the assumptions can be confirmed in further studies.
\end{abstract}

KEYWORDS: Co-creation; Persuasion; Observer Consume.

\title{
RESUMEN
}

En la revisión de la literatura sobre la co-creación se detectó vacíos teóricos relacionados con la respuesta observador del consumidor (que no participan en el proceso de co-creación) resultados para co-creación. El objetivo de esta investigación es estudiar el efecto de informar a la co-creación (empresa / consumidor y la empresa / especialista) de producto como persuasión del consumidor observador, teniendo en cuenta los diferentes recursos de la propaganda. En dos experimentos se manipulan las variables "tipo de asociado en la co-creación" (consumidores / expertos) y "tipo de mensaje de apelación" (racional / emocional). Los resultados no comprobaron los efectos esperados. Sin embargo, las medias de las medidas de persuasión apuntan que las hipótesis formuladas pueden ser confirmadas en estudios posteriores. 


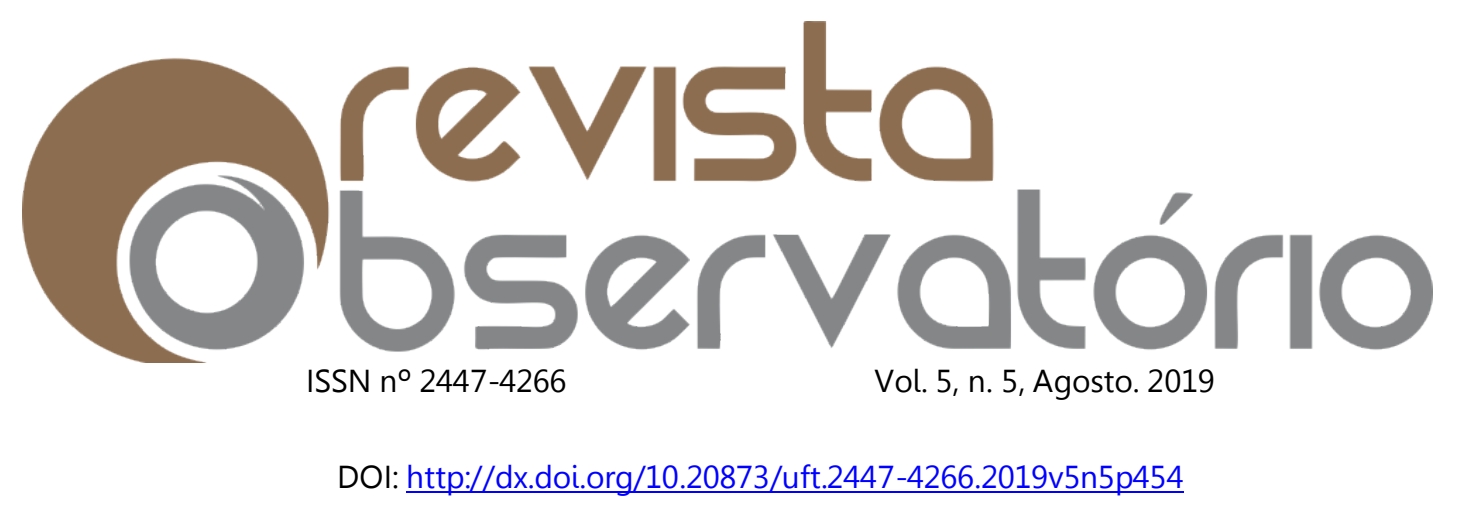

PALABRAS CLAVE: Co-creación; Persuasión; Consumidor observador;

Recebido em: 29.04.2019. Aceito em: 12.06.2019. Publicado em: 01.08.2019. 


\section{Obseristo \\ ISSN n 2447-4266 Vol. 5, n. 5, Agosto. 2019}

DOI: http://dx.doi.org/10.20873/uft.2447-4266.2019v5n5p454

\section{INTRODUÇÃO}

A cocriação de valor, ligada ao Processo de Desenvolvimento de Produtos (PDP), mostra-se uma boa opção na inovação. Tradicionalmente, fornecedores produziam bens e serviços, e os consumidores compravam-nos (PAYNE; STORBACKA; PENNIE, 2009; MOLLER; HALINEN, 2018). Hoje, O PDP tradicional estaria evoluindo para um Processo de Cocriação de Valor (PCV) por meio de interações entre múltiplos stakeholders em redes de valor, um sistema de cocriação de valor interconectado (BARTL; JAWECKI; WIEGANDT, 2010). Nesse PCV haveria troca de conhecimentos e habilidades entre a empresa e seus consumidores, clientes e parceiros (VARGO; LUSH, 2004), que estariam engajados em diálogos durante todo o processo, desde o design até a entrega do produto (PAYNE; STORBACKA; PENNIE, 2009). A cocriação também acontece na interação entre indivíduos, consumidores e usuários que agem de forma independente ou a pedido de uma empresa (ZWASS, 2010). Por tanto, o produto cocriado com ou sem a participação da empresa, seria resultado de processos interativos e recíprocos entre parceiros de relacionamento e stakeholders (BALLANTYNE; FROW; VAREY; PAYNE, 2011; GRÖNROOS, 2011; TZOKAS; SAREN, 1999; MOLLER; HALINEN, 2018).

O estudo dos efeitos da cocriação se destaca entre as prioridades de pesquisa apontadas por Zwass (2010). Em consonância, a revisão da literatura sobre cocriação permitiu identificar três lacunas teóricas, sintetizadas aqui, como falta de conhecimento sobre: i) a avaliação do resultado da cocriação de produtos (bens) consumidor/empresa, na perspectiva do consumidor observador (consumidor que não participou do processo de cocriação); ii) a avaliação do resultado da cocriação empresa/especialistas (profissionais relacionados a uma categoria de produto), na perspectiva do consumidor observador; iii) a influência dos apelos da mensagem de propaganda (um dos elementos do gerenciamento 


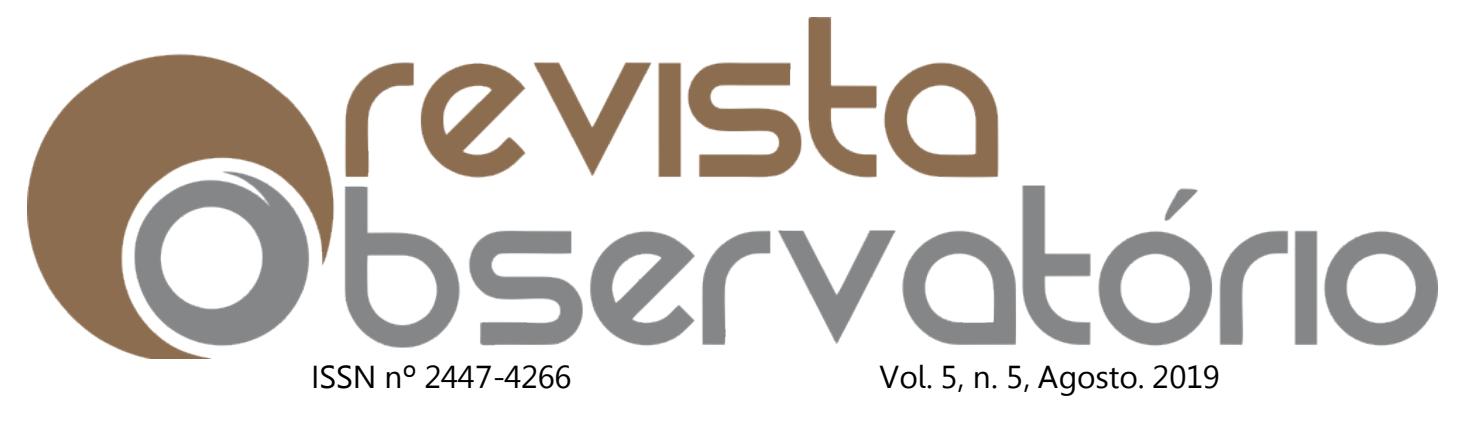

DOI: http://dx.doi.org/10.20873/uft.2447-4266.2019v5n5p454

de propaganda) no efeito de se informar a cocriação, na perspectiva do consumidor observador. Com o propósito atenuar as lacunas teóricas identificadas, o objetivo geral desta pesquisa é estudar o efeito se de informar a cocriação (empresa/consumidor e empresa/especialista) do produto, na persuasão do consumidor observador, considerando-se diferentes apelos de propaganda. Na revisão da literatura a seguir se evidenciam as lacunas teóricas da pesquisa sobre a cocriação e se formulam as hipóteses da pesquisa. $\mathrm{Na}$ sequência, se relatam dois experimentos por meio dos quais as hipóteses foram testadas. Finalmente se apresentam as conclusões, limitações e sugestões de pesquisa futura.

\section{REVISÃO DA LITERATURA}

\subsection{Cocriação: oportunidades de pesquisa}

Entre a diversidade de parceiros junto aos quais uma empresa pode cocriar valor, o papel do comprador se destaca, levando a definições de cocriação mais focadas. Nessa linha, a cocriação de valor envolveria interação entre consumidores/clientes (pessoas e organizações, respectivamente) e empresas com acesso bilateral de informações, em que a experiência individual de cada consumidor/cliente, em um determinado tempo e momento, resultaria na criação e definição do valor a ser agregado ao bem/serviço (PRAHALAD; RAMASWAMY, 2004). Em uma definição restrita ao marketing B2C (Business to Consumer), cocriação seria a decisão estratégica de incorporar as competências do consumidor ao PDP, ação também denominada coprodução no setor serviços (VARGO; LUSH, 2004). Alguns outros termos representam variadas formas de participação do consumidor em diversas etapas do PDP: prosumption (KOTLER, 


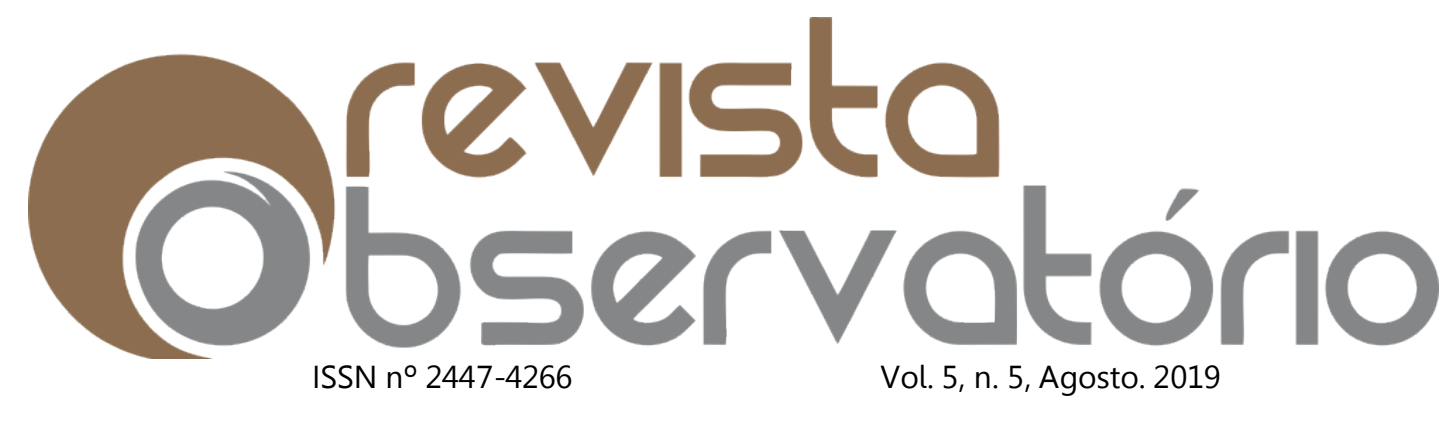

DOI: http://dx.doi.org/10.20873/uft.2447-4266.2019v5n5p454

1986; XIE; BAGOZZI; TROYE, 2008), self design e user design, customer criativity e self production.

Sobre cocriação com o consumidor, estudos são frequentes (VON HIPPEL, 2007; NUTTAVUTHISI, 2010) alguns deles focando especificamente o setor de serviços (CHATHOTH; ALTINAY; HARRINGTON; OKUMUS; CHAN, 2013; ELG; ENGSTRÖM; WITELL; POKSINSKA, 2012; MOLLER; HALINEN, 2018; AKMAN; PLEWA; CONDUIT, 2018). A cocriação empresa/consumidor traria benefícios a ambas as partes. Em geral, os estudos confirmam que a cocriação leva à fabricação de produtos mais adequados às necessidades do comprador/consumidor (PRANDELLI; VERONA; RACCAGNI, 2006; PRAHALAD; RAMASWAMY, 2004; FOTINO; CALABRESE; LETTIERI, 2018). Também, processos de cocriação por meio de concursos levantariam melhores ideias e a um custo menor do que os tradicionais grupos de foco, bem como a bons resultados financeiros (ZWASS, 2010).

Do lado do consumidor, seriam melhores as avaliações do produto cocriado por quem participou do processo de cocriação (TROYE; SUPPHELLEN, 2012). Por exemplo, encontrou-se que o consumidor cocriador do mix de produtos de uma empresa (escolhe junto à organização os produtos que devem ser vendidos) apresenta demanda mais forte por esses produtos, inclusive quando a qualidade dos produtos por ele escolhidos é idêntica à de outros em cujo processo de escolha ele não participou. No entanto, esses resultados não podem ser generalizados a todas as situações. Alerta-se para a necessidade de se comprovar tais efeitos em tarefas mais demandantes para o consumidor, pois o mencionado estudo contemplou uma tarefa simples. Atendendo o alerta, o foco desta pesquisa é na cocriação de produtos.

$\mathrm{Se}$, de um lado, sobre a avaliação do resultado da cocriação pelos participantes do processo de cocriação os estudos são conclusivos e alentadores 


\section{Observisto \\ ISSN n² 2447-4266 \\ Vol. 5, n. 5, Agosto. 2019}

DOI: http://dx.doi.org/10.20873/uft.2447-4266.2019v5n5p454

para as empresas, o mesmo não se pode dizer sobre a avaliação do resultado da cocriação pelos consumidores que não participaram do processo de cocriação. Apenas um trabalho foi localizado com consumidores observadores do processo de cocriação (consumidores que não participaram do processo de cocriação, mas de alguma forma são expostos a produtos cocriados) (THOMPSON; MALAVIYA, 2013). Todavia, essa pesquisa tratou da cocriação empresa/consumidor de propaganda de produtos da empresa e não da cocriação dos produtos em si. Nesse recorte, os resultados mostram que os consumidores podem reagir negativamente ao resultado da cocriação, por não considerarem outros consumidores tecnicamente aptos para criar uma propaganda. Já o efeito da cocriação na avaliação do produto cocriado, da perspectiva do consumidor observador, ainda não foi objeto de estudo. Daí, a primeira lacuna teórica identificada sintetiza-se na falta de conhecimento sobre o efeito da cocriação de produtos (bens) na perspectiva do consumidor observador.

Os estudos relacionados a outros stakeholders como parceiros de cocriação são menos comuns. Na maioria deles, os parceiros de cocriação são os fornecedores do fabricante e o foco das pesquisas é no processo de parceria entre as empresas. Bom relacionamento entre os parceiros de cocriação frequentemente levaria a excelentes resultados e ideias criativas. Por outro lado, estudos com outros parceiros, que não fornecedores, são raros. Há o caso da Lego em que foram analisadas as relações dessa empresa com vários stakeholders durante o processo de criação e desenvolvimento da linha da Arquitetura (GYRD-JONES; KORNUM, 2013). Destaca-se nesse trabalho a participação de arquitetos renomeados como parceiros de cocriação. No entanto, nada se diz sobre o efeito da participação desses profissionais na avaliação dos produtos cocriados, na perspectiva do consumidor observador do processo de 


\section{Obseristo \\ ISSN n 2447-4266 Vol. 5, n. 5, Agosto. 2019}

DOI: http://dx.doi.org/10.20873/uft.2447-4266.2019v5n5p454

cocriação. Essa é a segunda lacuna teórica aqui identificada e com a qual esta pesquisa pretende contribuir.

Enquanto o processo de cocriação tem sido estudado amplamente no ambiente online, há necessidade de se adotar uma abordagem mais abrangente. Nessa linha, o desafio é a incorporação de múltiplos stakeholders, não só ao PDP, mas a um novo modelo de gestão de marcas (GREGORY, 2007; MERZ; HE; VARGO, 2009; HATCH; SCHULTZ, 2010; GYRD-JONES; KORNUM, 2013; MOLLER; HALINEN, 2018; AKMAN; PLEWA; CONDUIT, 2018). Entende-se gestão de marcas como um sistema complexo que envolve decisões de $P \& D$, fabricação e logística, canais de distribuição e ações de comunicação, como propaganda e promoções (AAKER, 2007). As implicações da cocriação para a gestão de marcas permanecem inexploradas (GYRD-JONES; KORNUM, 2013), deixando dúvidas sobre se os benefícios da cocriação podem ir além da fabricação de produtos mais adequados às necessidades do comprador/consumidor (SIVASUBRAMANIAM; LIEBOWITZ; LACKMAN, 2012; AKMAN; PLEWA; CONDUIT, 2018), de um lado, e de resultados financeiros positivos para a empresa (Zwass, 2010; FOTINO; CALABRESE; LETTIERI, 2018), do outro.

Nesse contexto, argumenta-se aqui que a cocriação pode gerar benefícios indiretos para a organização quando incorporada à gestão de marcas. Especificamente, especula-se que, ações de comunicações de marketing, informando o consumidor observador, que o produto foi cocriado terá efeito na sua persuasão. No estudo sobre o efeito de informar que um anúncio foi cocriado com consumidores na perspectiva dos consumidores observadores, os autores consideraram a influência de dois fatores: identificação entre o parceiro de cocriação e o consumidor observador e ceticismo deste último com relação à capacidade do cocriador para desempenhar as tarefas relacionadas ao processo de cocriação (THOMPSON; MALAVIYA, 2013). Todavia, nada se diz sobre a 


\section{Observisto \\ ISSN n 2447-4266 Vol. 5, n. 5, Agosto. 2019}

DOI: http://dx.doi.org/10.20873/uft.2447-4266.2019v5n5p454

influência dos apelos da mensagem (um dos elementos do gerenciamento de propaganda) no efeito de se informar a cocriação. Essa é a terceira lacuna teórica direcionada nesta pesquisa.

Orientado pelas lacunas teóricas identificadas, o objetivo geral desta pesquisa é estudar o efeito da cocriação (empresa/consumidor e empresa/especialista) de produtos, na persuasão do consumidor observador, considerando-se diferentes apelos de propaganda.

\subsection{Desenvolvimento das hipóteses}

A Teoria da Difusão de Inovações (ROGERS, 2003) considera cinco determinantes da adoção de inovações pelo mercado: vantagem relativa, compatibilidade, complexidade, observabilidade e testabilidade. Quanto melhores as vantagens relativas, compatibilidade, observabilidade e testabilidade da inovação, maior será a probabilidade de adoção pelo consumidor. $\mathrm{Na}$ complexidade a relação é inversa. Esses determinantes da inovação são especialmente úteis no desenvolvimento de ações de comunicação de novos produtos (SHIMP, 2002). Pela Teoria da Difusão de Inovações, informar o consumidor sobre a participação de outros consumidores/especialistas no PDP poderia aumentar a sua percepção sobre a compatibilidade de um novo produto, levando-o à persuasão. $O$ consumidor seria levado a pensar que pelo fato de consumidores com valores, necessidades e experiências similares às dele terem participado do PDP, o produto cocriado será mais adequado. O mesmo aconteceria quando informado sobre a participação de um especialista relacionado à categoria de produto.

No âmbito do desenvolvimento de produtos, consumidores altamente envolvidos com a categoria se engajam em atividades de cocriação porque se sentem competentes para fazer contribuições valiosas. Logo, é possível que o 


\section{Obseristo \\ ISSN n 2447-4266 Vol. 5, n. 5, Agosto. 2019}

DOI: http://dx.doi.org/10.20873/uft.2447-4266.2019v5n5p454

consumidor que não participou do processo de cocriação reconheça essa capacidade de contribuição dos consumidores escolhidos pela empresa para participar da cocriação, aumentando a persuasão do produto cocriado. Todavia, não há na literatura evidências que suportem tal suposição. Na cocriação de anúncios encontrou-se que consumidores, não participantes da cocriação, não os percebem como mais confiáveis do que os anúncios criados por profissionais da empresa (THOMPSON; MALAVIYA, 2013). Ou seja, atribuir a criação de uma mensagem de propaganda a um consumidor dificultaria a persuasão, prejudicando a avaliação do anúncio e da marca. Entretanto, nesse caso o produto cocriado (anúncio) não está diretamente relacionado às necessidades de consumo e à capacidade técnica do cocriador (consumidor participante do processo de cocriação). Por isso, conjetura-se aqui que o efeito de informar ao consumidor sobre a cocriação de um produto diretamente relacionado às suas necessidades (na cocriação empresa-consumidor) e à capacidade técnica necessária (na cocriação empresa-especialista) pode ter efeito positivo na persuasão. Especificamente, a hipótese sobre o efeito da comunicação da cocriação de um produto aos consumidores é:

H1: Uma mensagem de propaganda que informa que o produto foi cocriado tem maior persuasão que uma mensagem de propaganda que não contém essa informação.

O efeito de se informar a cocriação da empresa com determinados parceiros (cocriação empresa/consumidor e cocriação empresa/especialista) na persuasão do consumidor observador do processo, pode variar devido à moderação de dois fatores propostos por Thompson e Malaviya (2013): identificação e ceticismo. O efeito de se informar a cocriação dependeria de: i) aumentar a identificação entre o parceiro de cocriação e o consumidor observador; ii) dificultar o ceticismo do consumidor observador com relação à 


\section{Observisto \\ ISSN n 2447-4266 Vol. 5, n. 5, Agosto. 2019}

DOI: http://dx.doi.org/10.20873/uft.2447-4266.2019v5n5p454

capacidade do consumidor cocriador para desempenhar as tarefas relacionadas ao processo de cocriação. Influenciar a identificação e o ceticismo do consumidor observador abrange decisões relacionadas a gerenciamento de propaganda. No trabalho de Thompson e Malaviya (2013), em função de o produto cocriado ter sido um anúncio de propaganda, seleção de mídia (por exemplo, informar a cocriação em tv ou em internet) e estrutura da execução (por exemplo, apresentar ou não informações sobre o cocriador) são os elementos de gerenciamento de propaganda apontados como influenciadores da identificação e do ceticismo. Nesta pesquisa, em que se trata do efeito de informar a cocriação de um produto de consumo na persuasão de consumidores observadores, consideramos mais adequado analisar a influência dos argumentos de venda apresentados na mensagem de propaganda. Para conjecturar sobre essa possível influência recorreu-se à teoria sobre gerenciamento de propaganda.

A escolha dos apelos, um dos elementos da gestão de propaganda, acompanha a definição da estratégia da mensagem, que pode ser cognitiva, afetiva, conativa e de marca. Implica decidir como atrair a atenção do consumidor potencial. Apelo é algo que faz com que uma oferta seja atrativa ou interessante para um individuo (WELLS; BURNETT; MORIARTY, 1995). Os comunicadores de marketing tentam guiar as pessoas à aceitação de crenças, atitudes e comportamentos usando apelos racionais (informação, argumentação) e/ou emocionais (como o sentimento de bem-estar, a felicidade) (SHIMP, 2002). O apelo racional assume que os consumidores tomam as suas decisões de compra com base no processamento racional de informações. O objetivo da propaganda seria prover as informações necessárias para auxiliar o consumidor a decidir. Os apelos racionais podem apresentar informações para gerar conhecimento sobre o produto ou motivos lógicos ou técnicos para suportar a proposta da marca. Os apelos emocionais almejam que o consumidor sinta uma ligação com a marca. 


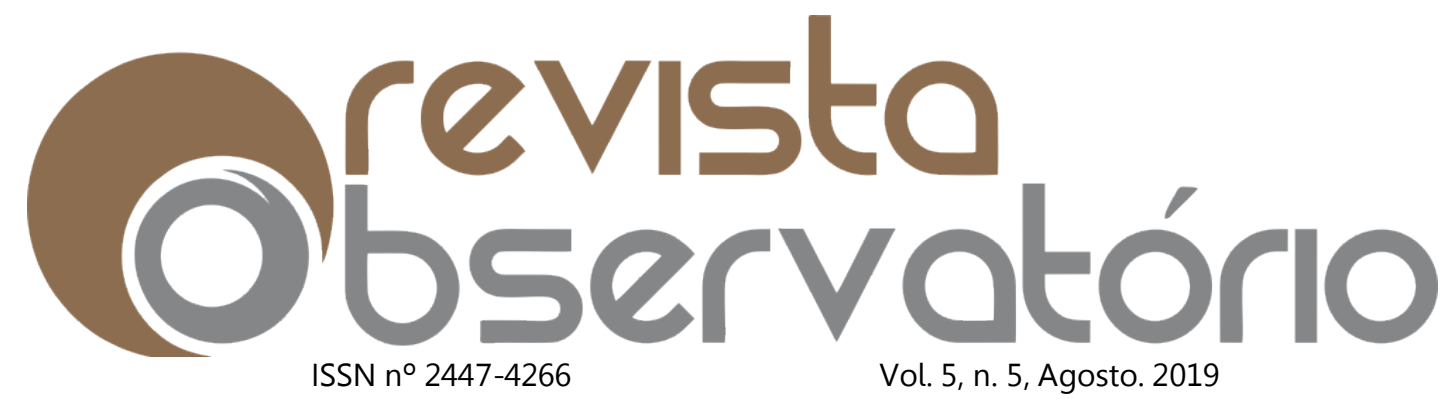

DOI: http://dx.doi.org/10.20873/uft.2447-4266.2019v5n5p454

Tentam evocar emoções e sentimentos, eventualmente levando o consumidor a lembrar do produto e escolhê-lo.

Por tanto, no âmbito desta pesquisa é possível que: i) informar o consumidor observador sobre a cocriação empresa/consumidor, utilizando-se apelos emocionais, seja mais persuasivo do que utilizando-se apelos racionais; ii) informar o consumidor observador sobre a cocriação empresa/especialista, utilizando-se apelos racionais, seja mais persuasivo do que utilizando-se apelos emocionais. Na primeira situação, enfatizando-se na mensagem os benefícios emocionais do produto (apelos emocionais), se estaria: a) aumentando a identificação entre o consumidor observador e o consumidor cocriador; b) diminuindo o ceticismo do consumidor observador com relação à capacidade do consumidor cocriador de um produto cujos benefícios são puramente emocionais. Na segunda, enfatizando-se na mensagem os atributos do produto (apelos racionais), se estaria: a) aumentando a identificação entre o produto cocriado e o especialista cocriador; b) diminuindo o ceticismo do consumidor observador com relação à capacidade do especialista cocriador de um produto cujos benefícios são puramente funcionais. Desta forma, a hipótese sobre a influência dos apelos da mensagem no efeito de se informar a cocriação é:

H2: Uma mensagem de propaganda que diz que o produto foi cocriado com consumidores (especialistas) é mais persuasiva quando a mensagem de propaganda apresenta apelo emocional (racional).

Às hipóteses formuladas subjazem dois pressupostos. O primeiro é que o consumidor observador se identifica com o consumidor cocriador, apenas pela utilização da palavra "consumidor". Essa identificação neutralizaria o ceticismo do consumidor observador quanto à capacidade do consumidor cocriador para realizar as tarefas do processo de cocriação. O segundo pressuposto é que os consumidores observadores perceberiam a identificação entre o especialista 


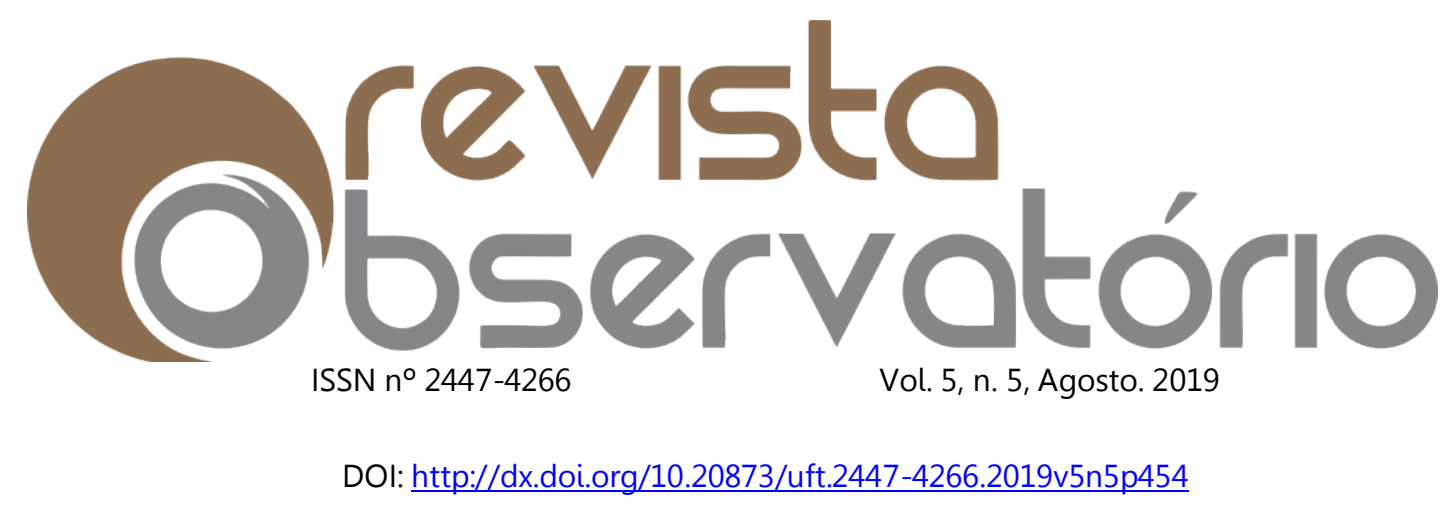

cocriador e os benefícios do produto cocriado, diminuindo o ceticismo quanto à capacidade do cocriador para realizar as tarefas do processo.

\section{ESTUDO 1 - MOCHILA}

\subsection{Método}

Foi realizado um experimento de desenho fatorial completo entre sujeitos 3 (tipo de parceiro de cocriação: consumidores, especialista, sem parceiro) X 2 (tipo de apelo: racional, emocional). Mochila foi a categoria de produto escolhida com base em dois critérios: i) relevante para jovens estudantes, potenciais participantes da pesquisa; ii) possível de ser anunciada utilizando-se apelos racionais e emocionais indistintamente.

\subsubsection{Procedimentos preliminares}

Para o preparo dos estímulos, foram identificados os atributos mais importantes de uma mochila, na perspectiva dos consumidores. Enviou-se um questionário fechado via e-mail a 400 alunos de duas escolas de ensinos médio e superior em SP. O respondente devia avaliar a importância de 21 atributos de uma mochila no momento da compra, atribuindo uma nota de 0 (nada importante) a 10 (muitíssimo importante). Houve possibilidade dele sugerir algum atributo que não estivesse na lista. Os atributos iniciais foram gerados em um brainstorming com 5 alunos de mestrado. Em 10 dias se obteve resposta de 95 estudantes. Os atributos considerados mais importantes na ocasião de compra de uma mochila são: resistência do tecido interno, resistência do tecido externo e zíperes, capacidade de suportar peso, impermeabilidade do tecido, conforto, tamanho peso, praticidade, divisões internas e cores. Dentre esses atributos 


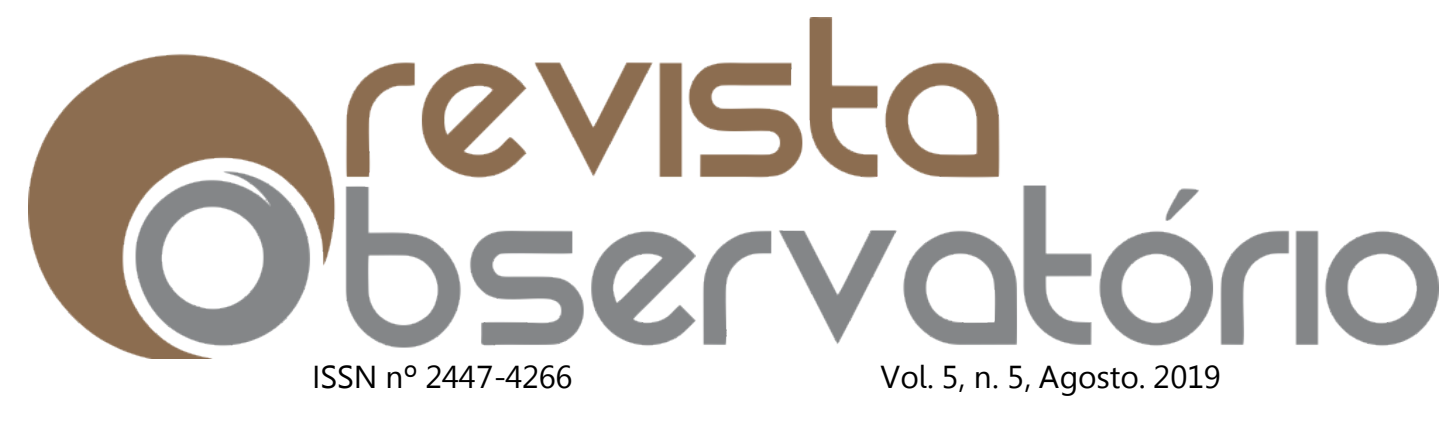

DOI: http://dx.doi.org/10.20873/uft.2447-4266.2019v5n5p454

foram selecionados aqueles que seriam utilizados para elaborar os anúncios de propaganda (estímulos do experimento).

Também, foi necessário avaliar o conhecimento dos potenciais participantes do experimento sobre o termo "cocriado". Para tanto, 28 estudantes foram expostos aleatoriamente ao anúncio de uma mochila informando apenas que o produto tinha sido "cocriado com consumidores" ou "cocriado com engenheiros têxteis". Em seguida foram questionados verbalmente sobre o termo "cocriado". Apenas um indivíduo não soube responder ao certo o que significava a expressão. Em função disso, assumiu-se que a maioria dos participantes do experimento não teria dificuldade para compreender a mensagem que seria veiculada nos anúncios (estímulos do experimento).

\subsubsection{Preparação dos estímulos}

Os estímulos deste experimento foram anúncios de propaganda de uma nova mochila. Para elaborar os anúncios, dois elementos da implementação da estratégia de propaganda foram considerados (SHIMP, 2002): i) escolha da promessa; ii) oferecimento de razões. O primeiro se refere ao(s) benefício(s) de um produto ou ideia principal de venda, que pode apelar para necessidades emocionais (com apelos emocionais) ou funcionais (com apelos racionais) do consumidor. Então, dentre os atributos identificados preliminarmente, foram selecionados dois tipos de atributos: emocionais (praticidade, espaço e estilo) e funcionais (conforto, segurança e impermeabilidade); para os quais foram criados apelos emocionais e racionais, respectivamente. $O$ texto representando o apelo emocional foi: "Prática e do tamanho ideal para caber tudo e mais. Um jeito maneiro de levar cada coisa em seu lugar com muito estilo". O texto do apelo racional foi: "Conforto e segurança para suas aventuras. Tecido totalmente impermeável e conforto máximo". O segundo elemento da implementação da 


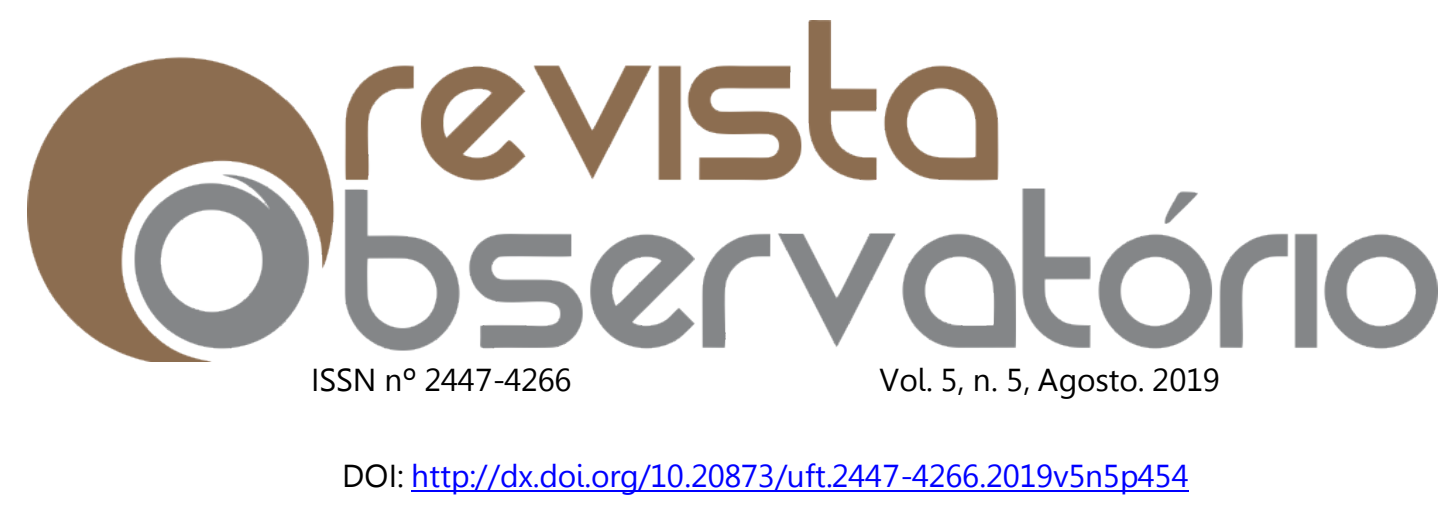

estratégia de propaganda, o oferecimento de razões, consiste em apresentar fatos relevantes sobre o produto que deem suporte à promessa. Para tanto, informações sobre tipo de parceiro de cocriação (consumidores/engenheiros têxteis) deram suporte aos benefícios prometidos. O cruzamento de tipo de apelo (emocional/racional) e tipo de parceiro de cocriação (consumidores, engenheiros têxteis, sem parceiro de cocriação) deu origem a seis anúncios. Optou-se por incluir o logo da marca Nike em todos eles, com o intuito de ganhar credibilidade.

\subsubsection{Mensurações}

As medidas de persuasão (variáveis dependentes) foram: "mudança de atitude em relação à marca", "atitude em relação ao anúncio" e "intenção de compra". Para a mensuração dos três construtos foram utilizadas escalas já validadas e disponíveis no Handbook de Escalas de Marketing (BRUNER; HENSEL, 1992). Para a mensuração dos construtos foram utilizadas escalas do Manual de Escalas de Marketing (BRUNER; HENSEL, 1992) do tipo Likert com 07 (sete) pontos, indo de 1 (discordo totalmente) até 7 (concordo totalmente).

\subsubsection{Coleta dos dados}

Participaram voluntariamente 230 estudantes de uma grande universidade de brasileira. Alunos de vários cursos de graduação em engenharia e administração foram convidados pessoalmente a participar de uma pesquisa sobre o lançamento de um novo produto. Após o convite, os alunos eram conduzidos a um laboratório com computadores. Passadas instruções, eles iniciavam a sua participação no experimento. Ao terminarem, os participantes receberam um bombom como agradecimento.

\subsubsection{Controle da manipulação}




\section{Obseristo \\ ISSN n 2447-4266 Vol. 5, n. 5, Agosto. 2019}

DOI: http://dx.doi.org/10.20873/uft.2447-4266.2019v5n5p454

Para verificar a correta compreensão dos estímulos foram feitas seis questões sobre as características da propaganda (apelos emocionais e racionais) e uma sobre a presença de informações de cocriação. $O$ intuito era eliminar os participantes que não perceberam os atributos emocionais ou racionais apresentados no anúncio a que foi exposto. Se o participante errasse mais de 3 questões, significaria que não prestou atenção nas características da mochila e, portanto, também poderia não ter percebido a informação sobre cocriação do produto no anúncio.

\section{RESULTADOS E DISCUSSÕES}

Para testar H1: Uma mensagem de propaganda que informa que o produto foi cocriado tem maior persuasão que uma mensagem de propaganda que não contém essa informação foi realizada uma comparação de médias. Para os anúncios informando que a mochila foi cocriada, as médias foram relativamente maiores. No entanto, essas diferenças não foram estatisticamente significantes. Na medida "mudança de atitude em relação à marca" a significância do teste de Levene foi 0.12 , portanto, usamos o teste $\mathrm{t}$ para variâncias iguais (equal variances assumed). $\mathrm{O}$ valor $\mathrm{t}=0.665$, com significância maior que 0.05 , não rejeita a hipótese nula de igualdade das médias, ou seja, não há diferenças estatisticamente significativas entre elas. Na média de "atitude em relação à propaganda" a significância do teste de Levene foi 0.017, portanto, usamos o teste $t$ assumindo que as variâncias não são iguais (equal variances not assumed). $\mathrm{O}$ valor $\mathrm{t}=0.982$, com significância maior que 0.05 , não rejeita a hipótese nula de igualdade das médias, ou seja, não há diferenças estatisticamente significativas entre elas. Por último, na medida de "Intenção comportamental" a significância do teste de Levene foi 0.726 , por tanto, usamos o teste $t$ assumindo que as variâncias são iguais (equal variances assumed). $\mathrm{O}$ valor $\mathrm{t}=0.644$, com 


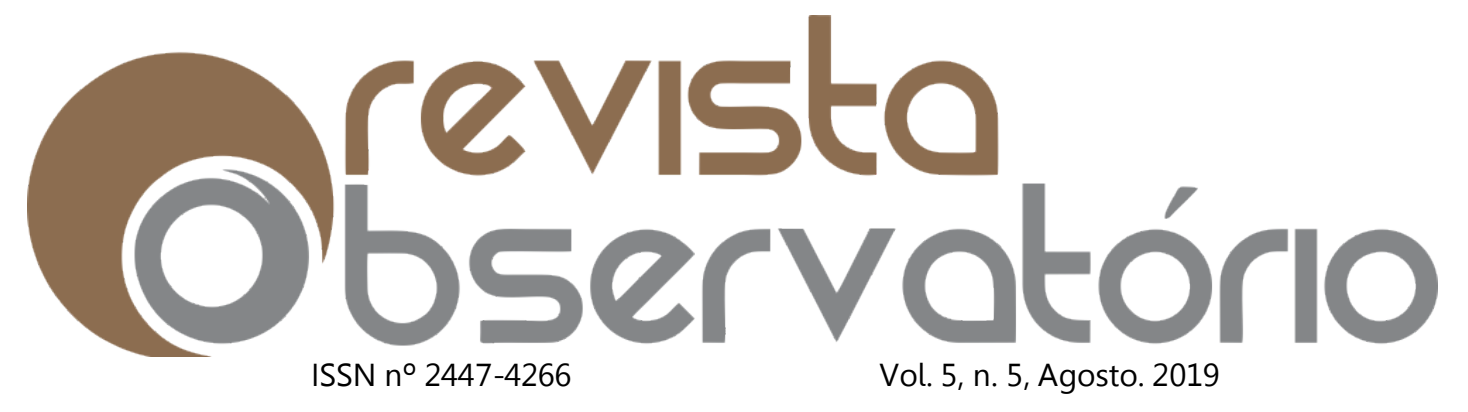

DOI: http://dx.doi.org/10.20873/uft.2447-4266.2019v5n5p454

significância maior que 0.05, não rejeita a hipótese nula de igualdade das médias, ou seja, não há diferenças estatisticamente significativas entre elas. Esses resultados oferecem evidências para rejeição de $\mathrm{H} 1$.

Para testar H2: Uma mensagem de propaganda que diz que o produto foi cocriado com consumidores (especialistas) é mais persuasiva quando a mensagem de propaganda apresenta apelo emocional (racional) utilizou-se a técnica estatística de análise de variância multivariada (MANOVA), com nível de significância a 5\%. Na formulação da MANOVA, foram incluídos os fatores relacionados ao tipo de parceiro de cocriação (consumidores, engenheiros têxteis e sem parceiro de cocriação) e ao tipo de apelo (emocional e funcional) e, como variáveis dependentes, "mudança de atitude em relação à marca", "atitude em relação à propaganda" e "intenção comportamental". Também verificou-se o efeito de interação entre as variáveis "tipo de apelo da mensagem" e "tipo de parceiro de cocriação".

O resultado da MANOVA para "atitude em relação à propaganda" apontou para um efeito principal da variável "tipo de apelo" $(F(1,224)=5,581 ; p<0,05)$. Também, para "intenção comportamental" houve efeito principal da variável "tipo de apelo" $(F(1,224)=9,980 ; p<0,05)$. Em "mudança de atitude em relação à marca", não se pode rejeitar $\mathrm{HO}(\mathrm{F}(1,224)=1,221$; n.s.). Ao se relacionar as três variáveis dependentes com a variável "tipo de parceiro de cocriação", não há nenhuma evidência para rejeitar $\mathrm{H0}$, dado que $\mathrm{F}$ foi menor que o $\mathrm{F} \neg$ crítico; "atitude em relação à propaganda" $(F(2,224)=0,521 ;$ n.s. $)$; "intenção comportamental" $(F(2,224)=1,028$; n.s.); "mudança de atitude em relação à marca" $(F(2,224)=0,297 ;$ n.s.). Na interação entre as variáveis "tipo de apelo da mensagem" e "tipo de parceiro de cocriação" ocorre o mesmo, ou seja, não há evidências para rejeitar $\mathrm{H} 0$, dado que $\mathrm{F}$ foi menor que o $\mathrm{F} \neg$ crítico em relação às três variáveis dependentes: "atitude em relação à propaganda" $(F(2,224)=1,016$; 


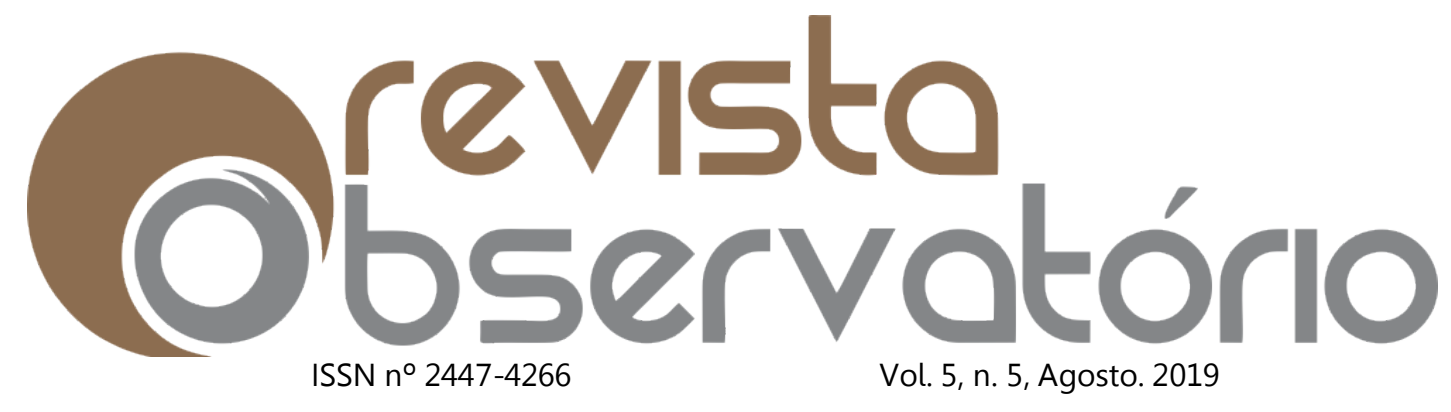

DOI: http://dx.doi.org/10.20873/uft.2447-4266.2019v5n5p454

n.s.); "intenção comportamental" $(F(2,224)=0,195$; n.s.); e "mudança de atitude em relação à marca" $(F(2,224)=0,107$; n.s.).

Apesar da rejeição das hipóteses pelas análises estatísticas, a observação das médias traz resultados interessantes. Como se pode observar na Tabela 1 a mensagem de propaganda informando que o produto foi cocriado com engenheiros têxteis apenas obteve média maior na variável "atitude em relação à propaganda". A variável dependente "mudança de atitude em relação à marca" apresentou média maior para o anúncio com apelos emocionais e parceiro de cocriação consumidores, conforme hipotetizado em H2. Já no que diz respeito ao anúncio com apelos funcionais, apresentou média maior para consumidores, contrapondo o hipotetizado em H2. Na atitude em relação à propaganda, o anúncio com apelos emocionais e parceiro de cocriação consumidores obteve média maior do que a do anúncio com apelos funcionais e parceiro de cocriação engenheiros têxteis, confirmando o hipotetizado em H2. Na terceira variável dependente, "intenções comportamentais", o anúncio com apelos emocionais e tipo de parceiro de cocriação consumidores obteve média maior do que a do anúncio com parceiro de cocriação engenheiros têxteis, corroborando o hipotetizado em H2. No entanto, o anúncio com apelos funcionais e parceiro de cocriação consumidores obteve também a maior média, contrapondo o hipotetizado em $\mathrm{H} 2$. Os resultados obtidos no estudo não permitem que se rejeitem integralmente as hipóteses. Pois há indícios de que, realizando-se alguns ajustes, as hipóteses testadas podem ser confirmadas em estudos posteriores.

Os resultados do primeiro experimento não confirmaram o efeito de se informar que um produto foi cocriado na persuasão do consumidor observador do processo de cocriação. Tampouco o efeito esperado da interação entre "tipo de apelo" e "tipo de parceiro de cocriação" na persuasão. No entanto, alguns problemas na execução do experimento podem ter distorcido os resultados. As 


\section{Observisto \\ ISSN n 2447-4266 Vol. 5, n. 5, Agosto. 2019}

DOI: http://dx.doi.org/10.20873/uft.2447-4266.2019v5n5p454

respostas à checagem da compreensão dos apelos mostraram que a maioria dos respondentes não percebeu os atributos racionais e emocionais como tais. Também a checagem da identificação da presença de informações sobre cocriação mostrou que a maioria dos participantes não a percebeu. Diante disso, um novo experimento foi planejado procurando se sanar as deficiências apontadas.

\section{ESTUDO 2 - TÊNIS}

\subsection{Método}

Foi realizado um experimento de desenho fatorial completo entre sujeitos 3 (tipo de parceiro de cocriação: consumidores, especialistas, sem parceiro de cocriação) X 2 (tipo de apelo: racional, emocional). A categoria de produto tênis foi escolhida com base em dois critérios: i) relevante para jovens estudantes, que seriam os potenciais participantes da pesquisa; ii) possível de ser anunciada utilizando-se apelo racional e emocional indistintamente.

\subsubsection{Procedimentos preliminares}

Para a categoria de produto selecionada foi necessário: i) determinar o grau de envolvimento do consumidor na escolha; ii) identificar os atributos importantes na ocasião de compra; iii) identificar o especialista mais capacitado a participar da cocriação. Um questionário aberto foi enviado via rede social para consumidores em potencial. $O$ respondente devia indicar: i) os atributos mais importantes; ii) responder 3 questões sobre seu envolvimento; iii) apontar o profissional mais capacitado para participar da cocriação. Responderam o questionário 84 indivíduos. Depois foram realizados três grupos focais com total de 23 alunos de graduação em Administração de uma universidade privada. $O$ objetivo foi checar os atributos iniciais referentes à categoria de produto. Os 


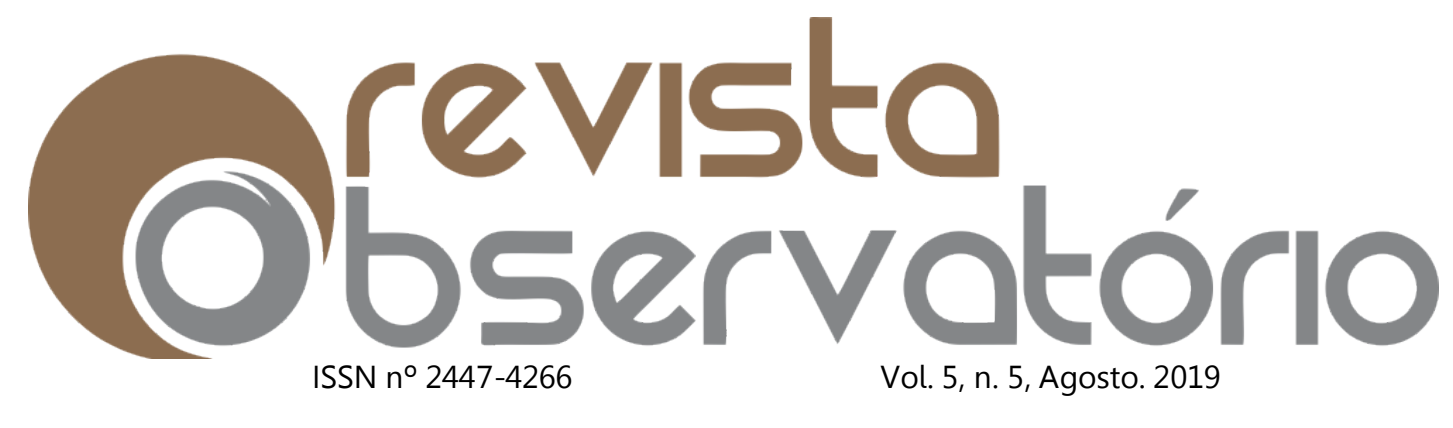

DOI: http://dx.doi.org/10.20873/uft.2447-4266.2019v5n5p454

participantes debateram sobre a cocriação de tênis. Houve intensa participação e comprovação do entendimento do "cocriado" e dos atributos funcionais e emocionais importantes na escolha de produtos nas categorias selecionadas.

Os resultados mostraram o tênis como o produto alto envolvimento. Os atributos considerados mais importantes na ocasião de compra de um tênis foram: conforto, beleza, durabilidade, design, amortecimento e absorção de impacto, cor e leveza. Dentre esses atributos foram selecionados aqueles que seriam utilizados para elaborar os anúncios de propaganda (estímulos do experimento). Ortopedista foi o especialista que teria participação relevante no desenvolvimento de um tênis. Admitiu-se que a maioria dos participantes do experimento não teria dificuldade para compreender a mensagem que seria veiculada nos anúncios (estímulos do experimento).

\subsubsection{Preparação dos estímulos}

Os estímulos deste experimento foram anúncios de propaganda de um novo tênis. Para elaborar os anúncios, do mesmo modo que no primeiro estudo, dois elementos da implementação da estratégia de propaganda foram considerados (SHIMP, 2002): i) escolha da promessa; ii) oferecimento de razões. Então, os atributos identificados preliminarmente como os mais importantes na ocasião de compra de um tênis foram classificados em atributos e benefícios. Seguindo-se a recomendação de Clow e Blaack (2002) os apelos racionais foram focados em atributos do produto e os apelos emocionais nos benefícios emocionais por ele proporcionados. Várias versões dos textos representando apelos racionais e emocionais foram testadas com o público-alvo até se chegar à versão final. $O$ texto representando o apelo racional para o tênis foi: um tênis resistente, anatômico e confortável, com novo solado antiderrapante que agarra em qualquer superfície. $O$ texto representando o apelo emocional para o tênis 


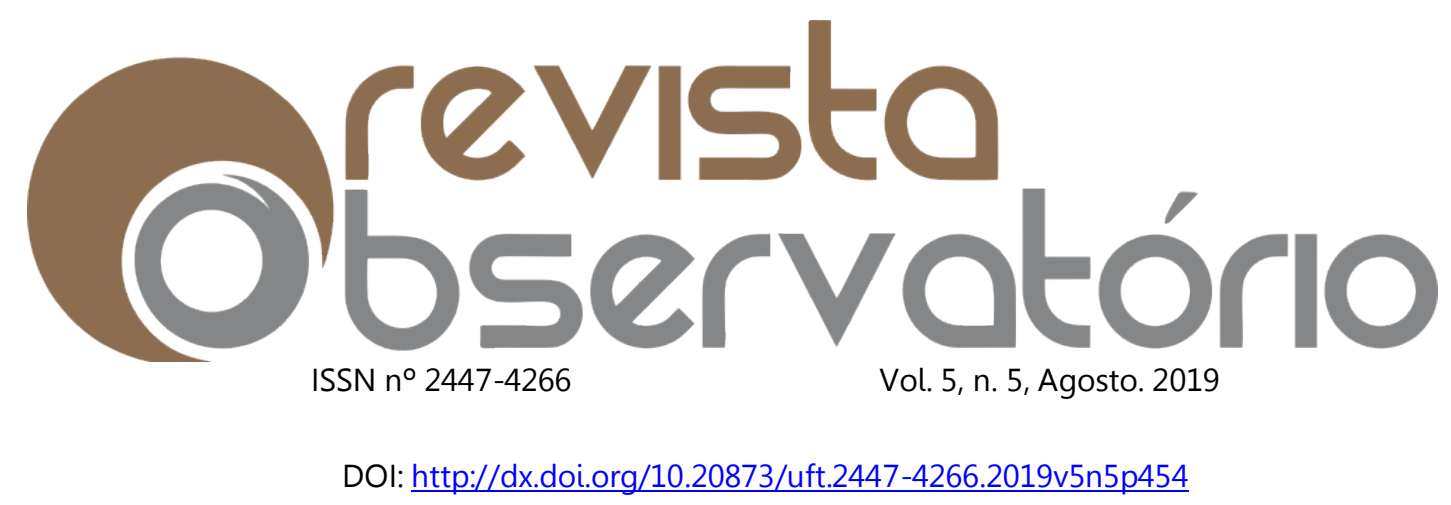

foi: um tênis que proporciona liberdade e novas emoções, fazendo você se sentir livre e confiante. Ao segundo elemento da implementação da estratégia de propaganda, o oferecimento das razões, correspondeu a informação sobre cocriação. Devido aos os problemas de compreensão do termo "cocriado" no primeiro estudo, optou-se por substituí-lo pelas palavras "criado e desenvolvido". A frase contendo essa informação nos anúncios foi: criado e desenvolvido com consumidores/ortopedistas. O cruzamento de tipo de apelo (emocional/racional) e do tipo de parceiro de cocriação (consumidores/ortopedistas/sem cocriação) deu origem a 6 (seis) anúncios. Optou-se por incluir o logo de marcas não comercializadas no Brasil.

\subsubsection{Mensurações}

As medidas de persuasão (variáveis dependentes) foram: "atitude em relação ao produto" e "atitude em relação à propaganda". Para a mensuração dos construtos foram utilizadas escalas do Manual de Escalas de Marketing (BRUNER; HENSEL, 1992), do tipo Likert com 07 (sete) pontos, indo de 1 (discordo totalmente) até 7 (concordo totalmente).

\subsubsection{Coleta dos dados}

Participaram voluntariamente 185 estudantes de uma grande universidade de brasileira. Alunos de vários cursos de graduação em engenharias e administração foram convidados pessoalmente a participar de uma pesquisa sobre o lançamento de um novo produto. Após o convite, os alunos eram conduzidos a um laboratório com computadores. Passadas instruções, eles iniciavam a sua participação no experimento. Ao terminarem, receberam um chocolate como agradecimento.

\subsubsection{Controle da manipulação}




\section{Obseristo \\ ISSN n 2447-4266 Vol. 5, n. 5, Agosto. 2019}

DOI: http://dx.doi.org/10.20873/uft.2447-4266.2019v5n5p454

Para verificar a atenção dos participantes em relação aos estímulos apresentados, foram feitas sete questões sobre os apelos da propaganda (racionais/emocionais) e sobre a participação do parceiro de cocriação (consumidores/ortopedistas) na criação e desenvolvimento do produto. Em função às respostas foram excluídos 38 sujeitos, pois erraram mais de 02 (duas) questões do controle da manipulação. Houve também, questões relacionadas ao envolvimento dos respondentes com a categoria de produto, com o intuito foi verificar o nível de envolvimento dos participantes.

\section{RESULTADOS E DISCUSSÕES}

Para testar H1: Uma mensagem de propaganda que informa que 0 produto foi cocriado tem maior persuasão que uma mensagem de propaganda que não contém essa informação, foi realizada comparação de médias. Para a "atitude com relação à propaganda" as médias dos anúncios que informam que o tênis foi cocriado são relativamente maiores. No entanto, não são estatisticamente significantes. Na medida "atitude em relação à propaganda" a significância do teste de Levene foi 0.30 , portanto, usamos o teste t para variâncias não iguais (equal variances not assumed). $\mathrm{O}$ valor $\mathrm{t}=1.293$, com significância maior que 0.05 , não rejeita a hipótese nula de igualdade das médias, ou seja, não há diferenças estatisticamente significativas entre elas. Na medida de "atitude em relação ao produto" a significância do teste de Levene foi 0.423 , portanto, usamos o teste t para variâncias iguais (equal variances assumed). 0 valor $\mathrm{t}=1.053$, com significância maior que 0.05 , não rejeita a hipótese nula de igualdade das médias, ou seja, não há evidências de diferenças significativas entre elas. Esses resultados oferecem evidências para rejeição de $\mathrm{H} 1$.

Na sequência, para testar H2: Uma mensagem de propaganda que diz que o produto foi cocriado com consumidores (especialistas) é mais persuasiva 


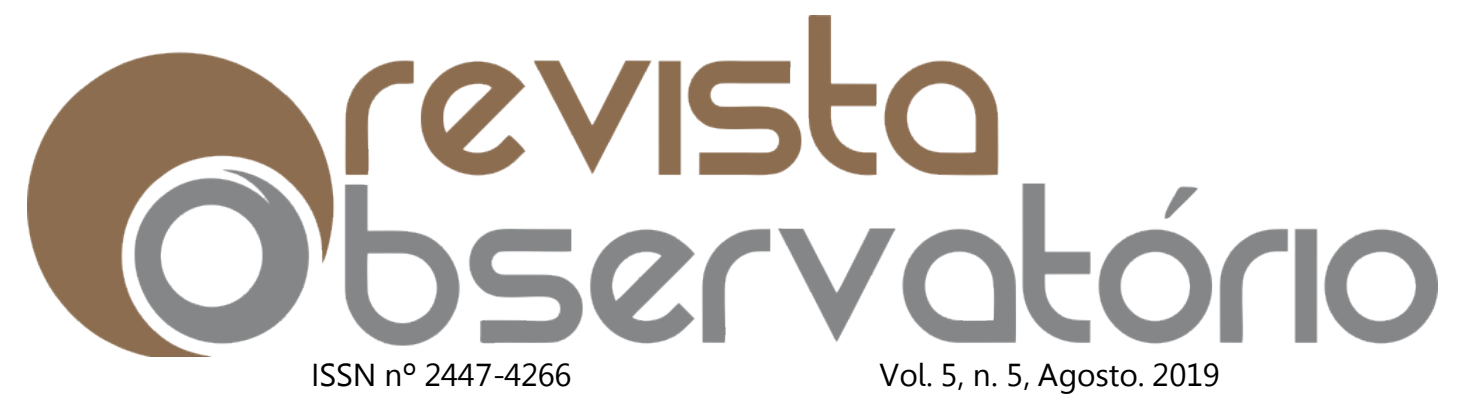

DOI: http://dx.doi.org/10.20873/uft.2447-4266.2019v5n5p454

quando a mensagem de propaganda apresenta apelo emocional (racional), utilizou-se a técnica estatística de análise de variância multivariada (MANOVA), com nível de significância a 5\%. Na formulação da MANOVA foram incluídos os fatores relacionados ao tipo de parceiro de cocriação (consumidores, ortopedistas e sem parceiro de cocriação) e ao tipo de apelo (emocional e racional) e, como variáveis dependentes, a "atitude em relação à propaganda" e a "atitude em relação ao produto". Verificou-se também o efeito de interação entre as variáveis "tipo de apelo da mensagem" e "tipo de parceiro de cocriação".

O resultado da MANOVA para "atitude em relação à propaganda" apontou um efeito principal da variável "tipo de apelo" $(F(1,141)=3,568$; n.s.). Da mesma forma, para "atitude em relação ao produto" $(F(1,141)=0,001$; n.s.), não sendo possível rejeitar HO. Ao se relacionar as variáveis dependentes com a variável "tipo de parceiro de cocriação", segue se a mesma tendência. Não há evidências para se rejeitar a hipótese nula, dado que F é menor que o F $\neg$ crítico; "atitude em relação à propaganda" $(F(2,141)=1,334$; n.s.); e "atitude em relação ao produto" $(F(2,141)=0,733$; n.s.). Na interação entre as variáveis ocorre o mesmo, ou seja, não é possível rejeitar $\mathrm{H} 0$, dado que $\mathrm{F}$ foi menor que o $\mathrm{F} \neg$ crítico em relação às variáveis dependentes: "atitude em relação à propaganda" $(F(2,141)=0,304$; n.s.) e "atitude em relação ao produto" $(F(2,141)=0,189 ;$ n.s.).

Os resultados do Estudo 2 não permitem que se rejeitem integralmente as hipóteses, pois há indícios de que, realizando-se alguns ajustes, as hipóteses testadas podem ser confirmadas. Os resultados do segundo experimento tampouco confirmaram o efeito de se informar que um produto foi cocriado na persuasão do consumidor observador do processo de cocriação. Do mesmo modo, o efeito esperado da interação entre "tipo de apelo" e "tipo de parceiro de cocriação" na persuasão, não foi confirmado. As questões de checagem da compreensão dos estímulos quanto aos apelos racionais e emocionais, os termos 


\section{Obseristo \\ ISSN n 2447-4266 Vol. 5, n. 5, Agosto. 2019}

DOI: http://dx.doi.org/10.20873/uft.2447-4266.2019v5n5p454

"criado e desenvolvido" e o envolvimento do participante com a categoria de produto, apresentaram níveis satisfatórios.

Em oposição ao Estudo 1, não houve problemas na execução do experimento que pudessem alterar os resultados. A explicação para as hipóteses formuladas terem sido rejeitadas pode estar nos pressupostos assumidos quanto a: identificação e ceticismo. Assumimos que o consumidor observador se identificaria com o consumidor cocriador, neutralizando seu ceticismo quanto à capacidade do consumidor cocriador para realizar as tarefas do processo. No entanto, isso pode não ter acontecido. É possível que a amplitude da palavra "consumidores", como parceiros de cocriação, não tenha gerado a identificação (dos consumidores observadores) necessária para o efeito existir. No que diz respeito à mensagem de propaganda informando a cocriação com especialistas, assumimos com base nos pré-testes realizados, que o "ortopedista" seria o especialista mais indicado para participar do processo de criação e desenvolvimento do tênis. No entanto, é possível que o modelo do produto apresentado no anúncio (aventura) criado e desenvolvido com ortopedistas, pode não ter sido relacionado aos atributos e/ou benefícios explícitos na mensagem da propaganda.

\section{CONSIDERAÇÕES FINAIS E RECOMENDAÇÕES}

O objetivo geral desta pesquisa foi estudar o efeito de se informar a cocriação (empresa/consumidor e empresa/especialista) do produto, na persuasão do consumidor observador, considerando-se diferentes apelos de propaganda. Para tanto, as hipóteses testadas foram: H1: Uma mensagem de propaganda que informa que o produto foi cocriado tem maior persuasão que uma mensagem de propaganda que não contém essa informação e H2: Uma mensagem de propaganda que diz que o produto foi cocriado com 


\section{Observisto \\ ISSN n 2447-4266 Vol. 5, n. 5, Agosto. 2019}

DOI: http://dx.doi.org/10.20873/uft.2447-4266.2019v5n5p454

consumidores (especialistas) é mais persuasiva quando a mensagem de propaganda apresenta apelo emocional (racional). Os resultados rejeitaram as hipóteses formuladas, no entanto, há indícios que apontam que as hipóteses testadas podem ser confirmadas em estudos posteriores. Pois, as médias das medidas de persuasão foram superiores para os anúncios que apresentaram informação de cocriação, nos dois experimentos realizados.

Como contribuição teórica, esta pesquisa traz alguns subsídios. Em primeiro lugar, a revisão da literatura mostrou não haver estudos sobre a avaliação do resultado da cocriação (consumidor/empresa) de produtos (bens), pelo consumidor observador. Estudos prévios trazem a perspectiva do consumidor que participou do processo de cocriação (TROYE; SUPPHELLEN, 2012), mas não de quem não participou e de alguma forma foi exposto ao resultado da cocriação. Os resultados, ainda não conclusivos, desta pesquisa mostram que a participação de consumidores no processo de desenvolvimento de um produto não afeta a sua avaliação por parte do consumidor observador.

Em segundo lugar, a revisão da literatura mostrou carência de trabalhos abordando a parceria de cocriação com especialistas e o efeito disso na avaliação do resultado da cocriação. Sobre essa parceria, já consolidada na prática pela Lego (GYRD-JONES; KORNUM, 2013), nada se sabe da perspectiva do consumidor observador. Os resultados desta pesquisa mostram melhores avaliações do produto cocriado com especialistas do que com consumidores. Adicionalmente, os apelos racionais parecem ser mais efetivos quando se informa a cocriação com especialistas. Por fim, outra contribuição teórica está na inclusão da informação sobre a cocriação do produto como um elemento da comunicação de marketing. Diante do fato de as implicações da cocriação para a gestão de marcas permanecerem inexploradas (GYRD-JONES; KORNUM, 2013), argumentou-se aqui que a cocriação teria benefícios indiretos quando incorporada à gestão de 


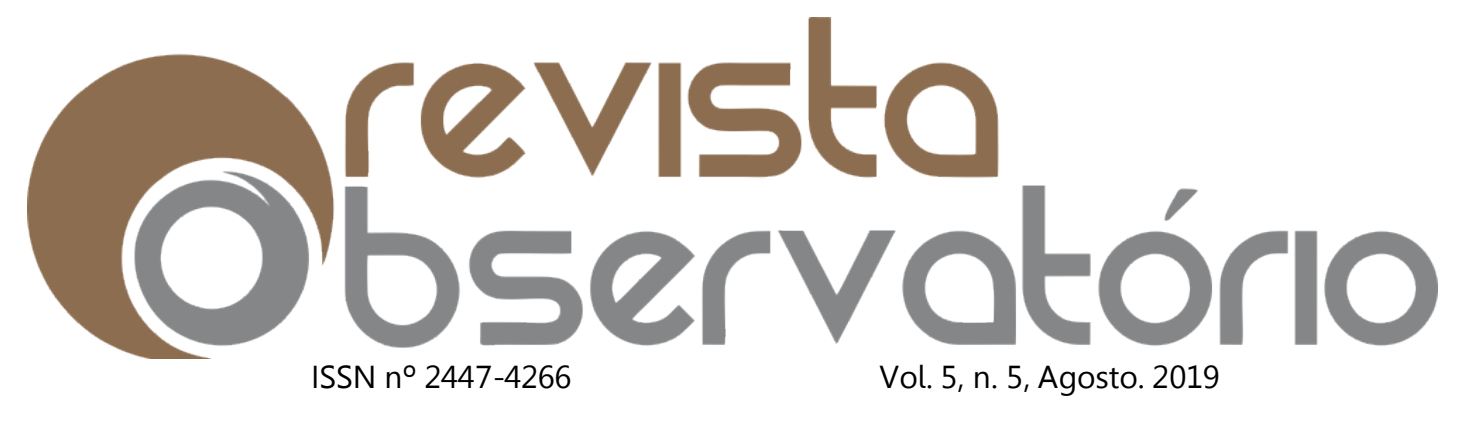

DOI: http://dx.doi.org/10.20873/uft.2447-4266.2019v5n5p454

marca. Os resultados mostram que os consumidores observadores consideram importante a participação de consumidores e especialistas no processo de desenvolvimento do produto. No entanto, informar a cocriação, utilizando-se diferentes apelos (racionais e emocionais) não teve efeito na persuasão do consumidor observador.

Pelos resultados dos estudos relatados neste artigo, confirma-se necessidade de mais pesquisa sobre o assunto. Propõe-se seguir a sugestão de Thompson e Malaviya (2013) e manipular a identificação entre o consumidor observador e o consumidor cocriador. Com isso, espera-se que o efeito da cocriação apareça. Também é possível que o efeito da cocriação com especialistas possa ser mais evidente em categorias de produto em que há grande insatisfação com as alternativas disponíveis. Nesse caso, a participação de um especialista seria ainda mais adequada, sendo possível o efeito a informação da cocriação na persuasão. Na mesma linha, é possível que manipular a satisfação do consumidor observador com a categoria de produto cocriada influencie o efeito da informação sobre cocriação. Essas são questões a ser abordadas em futuras pesquisas.

\section{Referências}

AAKER, D. A. Como construir marcas líderes. Porto Alegre: Bookman, 2007. AKMAN, H; PLEWA, C; CONDUIT, J. Co-creating value in online innovation communities. European Journal of Marketing, 2018.

BALLANTYNE, D. et al. Value propositions as communication practice: taking a wider view. Industrial Marketing Management, 40, n. 2, p. 202-210, 2011.

BARTL, M.; JAWECKI, G.; WIEGANDT, P. Co-creation in new product development: conceptual framework and application in the automotive industry. Proceedings of the R\&D, 2010.

BRUNER, G. C. I.; HENSEL, P. Marketing Scales Handbook: A Compilation of MultiItem Measures. Carbondale: GCBII Productions, v. 5, 1992. 


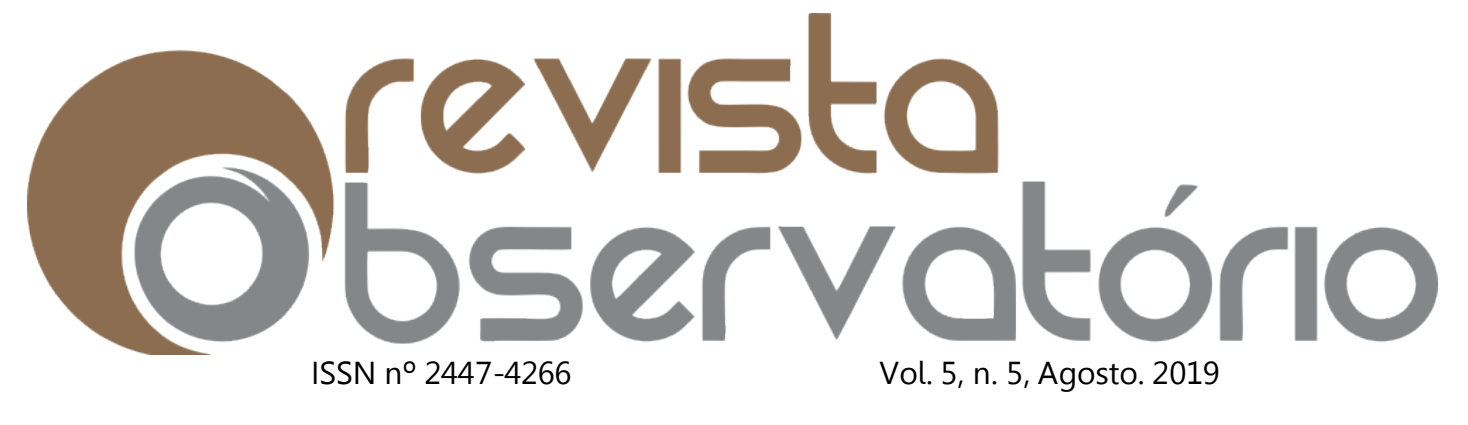

DOI: http://dx.doi.org/10.20873/uft.2447-4266.2019v5n5p454

CHATHOTH, P. et al. Co-production versus co-creation: a process based continuum in the hotel service context. International Journal of Hospitality Management, 32, 2013.

CLOW, K. E.; BAACK, D. Integrated advertising. promotion. \& marketing communications. New Jersey: Prentice Hall, 2002.

ELG, M. et al. Co-creation and learning in health-care service development. Journal of Service Management, 23, n. 3, p. 328-343, 2012.

FOTINO, F.; CALABRESE, M.; LETTIERI, M. Co-creating value in urban public policy contexts: A different approach. Land use policy, v. 79, p. 20-29, 2018.

GREGORY, A. Involving stakeholders in developing corporate brands: the communication dimension. Journal of Marketing Management, 23, n. 1-2, p. 5973, 2007.

GRÖNROOS, C. Value co-creation in service logic: a critical analysis. Marketing Theory, 11, n. 13, p. 279-301, 2011.

GYRD-JONES, R. I.; KORNUM, N. Managing the co-created brand: Value and cultural complementarity in online and offline multi-stakeholder ecosystems. Journal of Business Research, 66, p. 1484-1493, 2013.

HATCH, M. J.; SCHULTZ, M. Toward a theory of brand co-creation with implications for brand governace. Journal of Brand Management, 17, n. 8, p. 590604, 2010.

KOTLER, P. Prosumers: A New Type of Consumer. The Futurist, 20, p. 24-28, 1986. MERZ, M. A.; HE, Y.; VARGO, S. L. The evolving brand logic: a service-dominat logic perspective. Journal of the Academy of Marketing Science, 37, p. 328-344, 2009. MÖLLER, K; HALINEN, A. IMP thinking and IMM: Co-creating value for business marketing. v. 69 , p. 18-31, 2018.

NUTTAVUTHISI, K. If you can't beat them, let them join: the development of strategies to foster consumer's co-creative practices. Business Horizons, 53, p. 315-324, 2010.

PAYNE, A. et al. Co-creating brands: diagnosing and designing the relationship experience. Journal of Business Research, 27, n. 4, p. 412-432, 2009.

PRAHALAD, C.; RAMASWAMY, V. Co-creation experiences: The next practice in value creation. Journal of Interactive Marketing, 18, n. 3, p. 5-14, 2004.

PRANDELLI, E.; VERONA, G.; RACCAGNI, D. Diffusion of web-based product innovation. Califoronia Management Review, 48, n. 4, p. 109-135, 2006.

ROGERS, E. M. Diffusion of Innovations. 5. ed. Nova lorque: Free Press, 2003. 


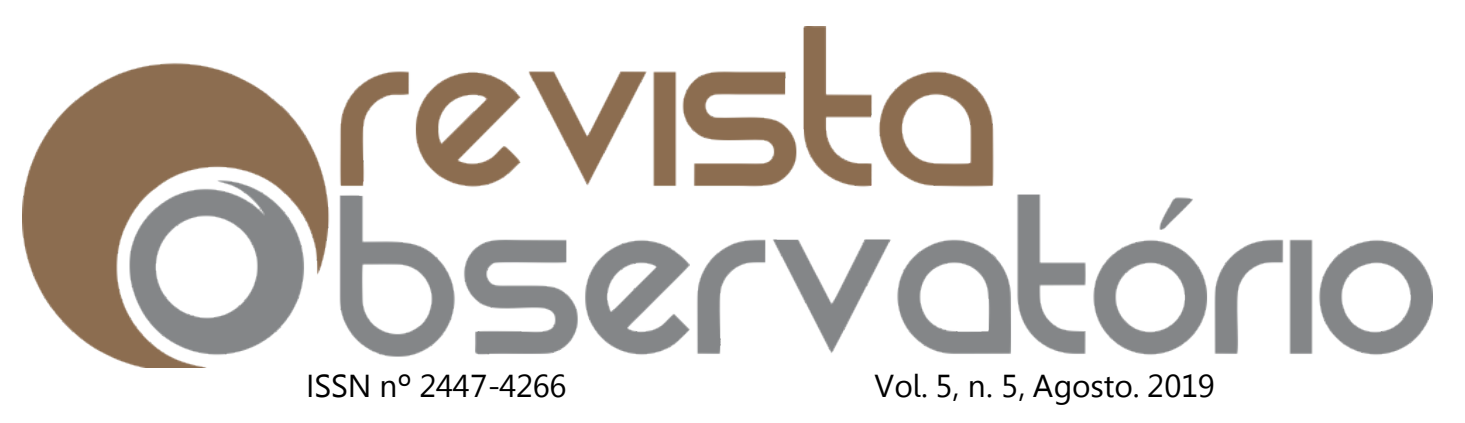

DOI: http://dx.doi.org/10.20873/uft.2447-4266.2019v5n5p454

SHIMP, T. A. Propaganda e promoção. São Paulo: Bookman, 2002.

SIVASUBRAMANIAM, N.; LIEBOWITZ, S. J.; LACKMAN, C. L. Determinants of new product development team performance: a meta-analytic review. Journal of Product and Innovation Management, 29, n. 5, p. 803-820, 2012.

THOMPSON, D. V.; MALAVIYA, P. Consume-generated ads: does awareness of advertising co-creation heip or hurt persuasion. Journal of Marketing, 77, n. May, p. 33-47, 2013.

TROYE, S.; SUPPHELLEN, M. Consumer Participation in Coproduction: "I Made It Myself" Effects on Consumers' Sensory Perceptions and Evaluations of Outcome and Input Product. Journal of Marketing, v. 76, p. 33-46, 2012.

TZOKAS, N.; SAREN, M. Value transformation in relationship marketing. Australian Marketing Journal, 7, n. 1, p. 52-62, 1999.

VARGO, S. L.; LUSH, R. F. Evolving to a new dominant logic for marketing. Journal of Marketing, 1, p. 1-17, 2004.

VON HIPPEL, E. Horizontal innovation networks: by and for users. Industrial and Corporate Change, 16, n. 2, p. 293-315, 2007.

WELLS, W.; BURNETT, J.; MORIARTY, S. Advertising: principles and practice. 3. ed. New Jersey: Prentice Hall, 1995.

XIE, C.; BAGOZZI, R.; TROYE, S. V. When consumers co-produce: the case of prosumption. Journal of the Academy of Marketing Science, 36, n. March, p. 109122, 2008.

ZWASS, V. Co-creation: toward a taxonomy and an integrated research perspective. International Journal of Electronic Commerce, 15, n. 1, p. 11-48, 2010. 